\title{
BYOE: Design and Development of Simple Robotic Arm
}

\section{Dr. Iftekhar Ibne Basith, Sam Houston State University}

Dr. Iftekhar Ibne Basith is an Assistant Professor in the Department of Engineering Technology at Sam Houston State University, Huntsville, TX, USA. Dr. Basith has a Ph.D and Masters in Electrical and Computer Engineering from University of Windsor, ON, Canada with concentration on 3D IC, MEMS and Testing. Dr. Basith has published several IEEE transactions, articles and conference proceedings over the last few years. His research interest lies on Robotics, Tesing of 3D IC, MEMS, Analog/ Mixed-Signal Devices, RF circuits, Low Power CMOS and Wireless Communication.

Mr. Brandon Marroquin, Sam Houston State University 


\author{
Design and Development of Simple Robotic Arm \\ ASEE 2020 Conference - DELOS Division - BYOE Session
}

\title{
Summary
}

In today's world there is an increasing need to create artificial arms where human interaction is difficult or impossible. In this paper we describe the implementation of a simple robotic arm capable of moving and lift some objects. The development of this arm is based on the Arduino UNO. The servos act as joints of the robotic arm which are controlled by corresponding potentiometer. We have used low torque servos here due to budget constraint and proof of concept; however more powerful servos can be integrated to pick heavy object. This particular robotic arm was designed with four degrees of freedom and programmed to accurately accomplish simple and light material lifting task as in the production line in any industry. However, it can be used as pharmacy-based drug-giving robots; in the medical sector and in automation systems. The generation of the human-like manipulation motions has been implemented and also tested successfully for the 4 degrees of freedom (DOF) arm of the humanoid robot. The presented approach does not consider the dynamics of the robot arm. This would be necessary to generate realistic velocity distribution for the manipulation motions.

The implemented prototype has the ability to move in 4 axis directions with 4 servo motors. The voltage across variable resistors is not completely linear rather a noisy one. Capacitors are used across each resistor to filter out this noise, as shown in figure 1. This voltage represents the control position and is fed into four ADC channels of Arduino to get corresponding digital values. The Arduino UNO $\mathrm{ADC}$ has a resolution of 10 bit, means it maps input voltages between 0 and $5 \mathrm{~V}$ into digital values between 0 and 1023; in other words, $4.9 \mathrm{mV}$ per unit. This project is very helpful for beginners who want to make a robotic arm with low cost.

\section{Objectives}

- Create artificial arms for different inhuman situation

- Motivate new students in robot development

- Design new ways to control robot parts

\section{Scope}

The result of creating new robot arms for different human situations will lead to safety and care; even more, in life or death. In addition, if we create a simple robotic arm controlled by a programmable microchip will motivate students in the robotic development. By the same token, With the technology we have at our disposal, it would be interesting to create new ways to control robotic parts, for example by placing sensors on a person's arm; even more, with the brain waves.

\section{Components Used}

We used several tools in our project. Basically Arduino Uno, servos motor and potentiometer are the key components of this project. The different components used in our project are described below accordingly

1. Arduino: We use Arduino as a main tool in our project. Arduino is open source platform; we used Arduino to successfully complete our project. Arduino consist both physical programmable circuit board and a piece of software. Arduino Uno has 14 digital input/output pins, USB connection, 6 analog inputs, reset button as shown in Figure 1(a). Arduino programming is an implementation of wiring.

2. Potentiometers: A potentiometer also referred to as pot may come in a wide variety of shapes and are used in many applications in your daily life, for example to control the audio volume of the radio. A pot is a manually adjustable variable resistor with three terminals. Figure 1(b) shows some examples of potentiometers. 


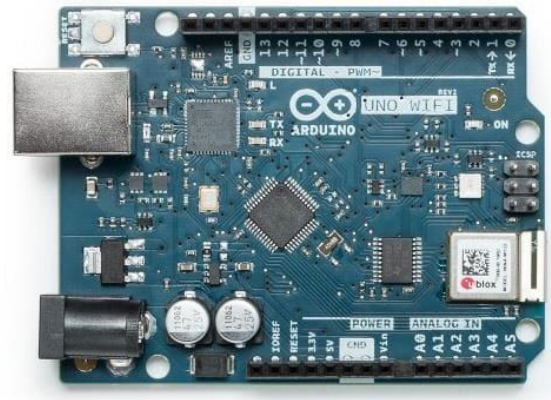

(a)

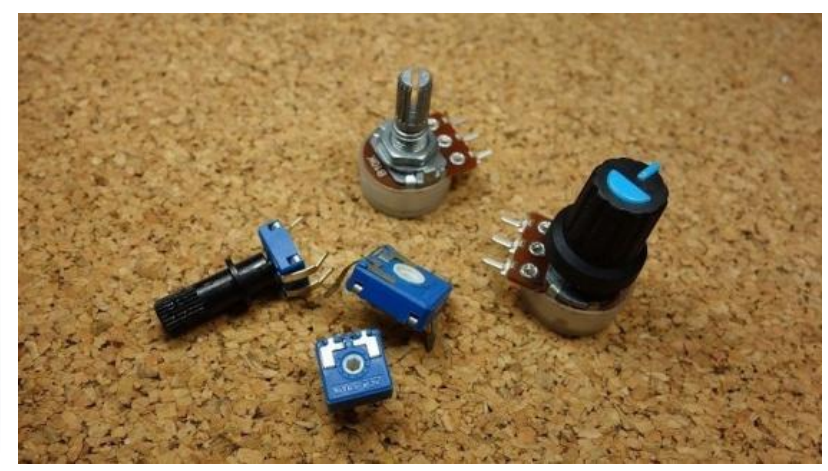

(b)
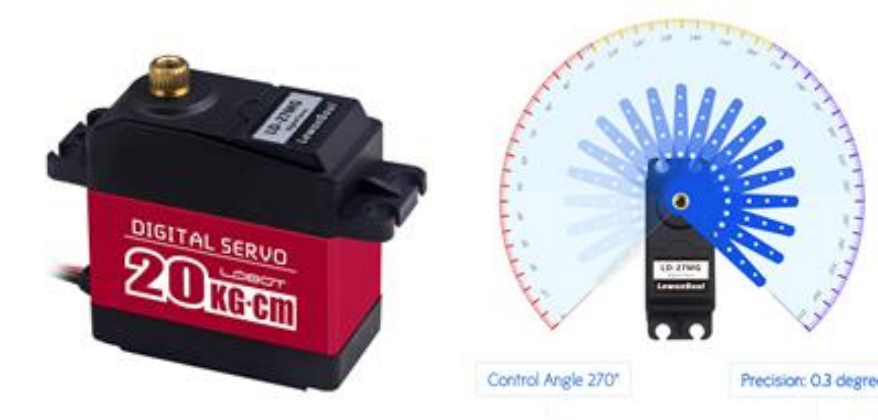

Control Angle 270

Precision 03 degree

(c)

Figure 1: Components used to build the prototype, (a) ARDUINO UNO, (b) Potentiometers, and (c) Servo Motors

3. Servo motors: We used small servo motors to control the movement. We connected it directly to an Arduino. Servos are extremely useful in robotics. The servo motors we used is small as you can see in Figure 1(c). It has built-in control circuitry, and is extremely powerful for the size: torque of $20 \mathrm{~kg} . \mathrm{cm}$ (277.6 oz·in) @ 6.6V with a dimension of $40 * 20 * 40.5 \mathrm{~mm}(1.57 * 0.78 * 1.59 \mathrm{inch})$. It also draws power proportional to the mechanical load. A lightly loaded servo therefore doesn't consume much energy. For power we need $+5 \mathrm{~V}$, connect to ground, and the white wire is the control wire. Servo motors are used in control systems such as fast operation, excessive axis movement, condition control and so on. They are highly sensitive and servo motors are used in conjunction with electronic or programmable circuits.

\section{Circuit Diagram}

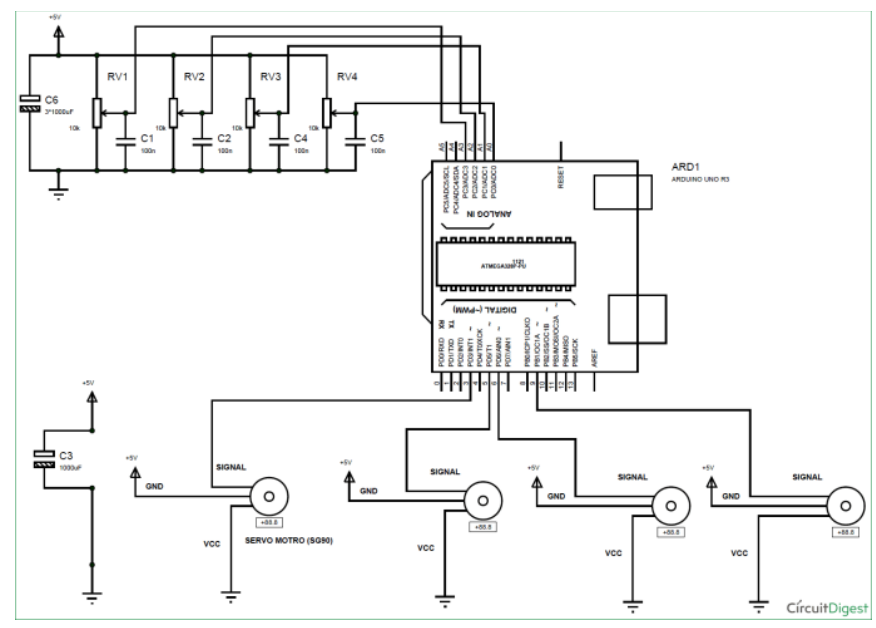

Figure 2: Circuit Diagram for the built prototype 


\section{Construction of robotic arm}

- The base of the robotic arm is made of 12 " x 24 " plexiglass. Next place a servo motor in the middle and glue screwed it in place. This servo acts as base of arm flat.

- Place a 2" 2 2" plexiglass on top of first servo and then place the second servo on this piece of board and glue and screw it in place.

- The other parts printed using the 3D printer.

- Add some rubber band to the end of the robotic finger to better grips.

- Use the circuit diagram for assemble the wiring and Arduino uno, set the variable resistor together for better control.

- For better results is recommended to use $9 \mathrm{~V}$ for the Arduino, also for the servo motors you need extra power supply of $5 \mathrm{~V}$.

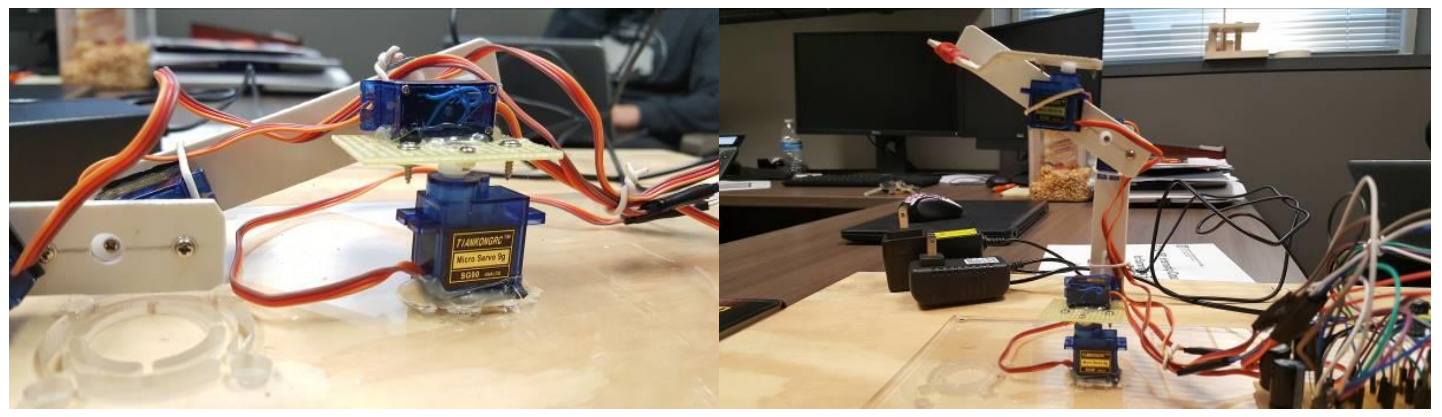

(a)

(b)

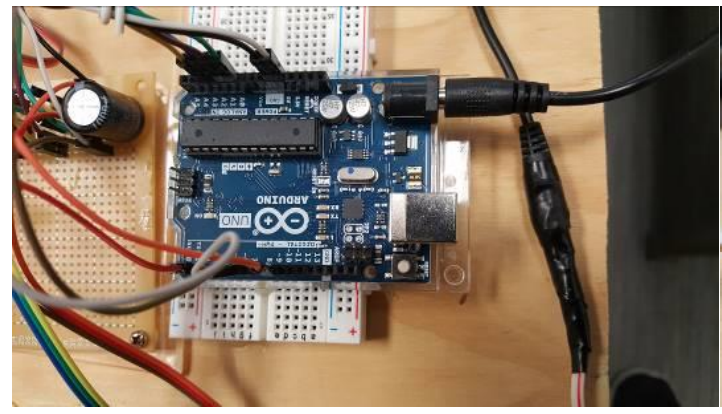

(c)

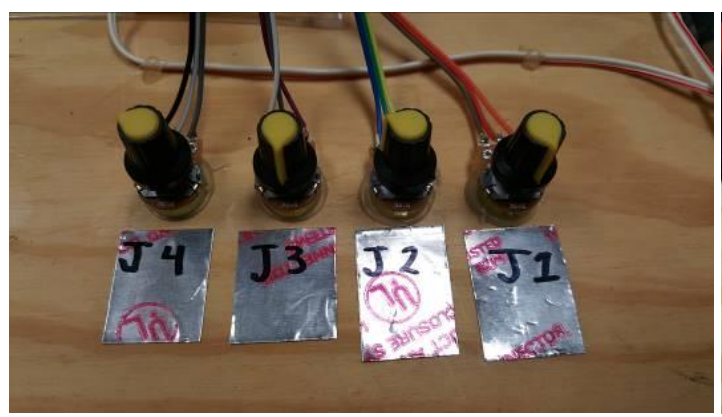

(e)

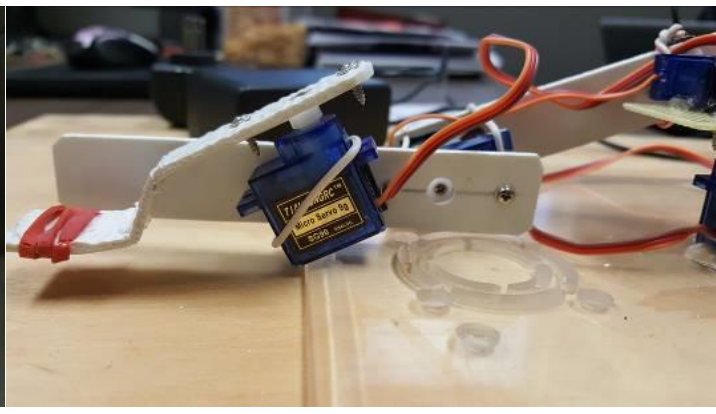

(d)

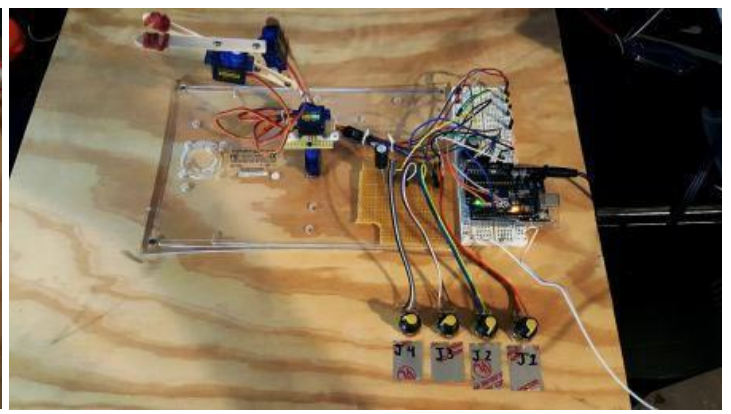

(f)

Figure 3 (a-f): Different steps of the implementation

\section{Operation of robotic arm}

There are four variable resistor pots provided to the user. And by rotating these four pots, we provide variable voltage at the ADC channels of Arduino UNO. So, the digital values of Arduino are under control of user. These digital values are mapped to adjust the servo motor position; hence the servo position is in control of user and by rotating these Pots user can move the joints of Robotic arm and can pick or grab any object. 
Bill of Materials

\begin{tabular}{|c|c|c|}
\hline & Description of Work & Costs \\
\hline Arduino Power Adapter & Supply power to the Arduino UNO & $\$ 9.00$ \\
\hline 4 10K Ohm Potentiometer & $\begin{array}{l}\text { Will control the position of the } \\
\text { robotic arm }\end{array}$ & $\$ 12.00$ \\
\hline Arduino UNO & Programable Microcontroller & $\$ 19.00$ \\
\hline 6 Miuzei Digital Servo Motors & Will move the robotic arm & $\$ 107$ \\
\hline PCB board & $\begin{array}{l}\text { For soldering wires and electronics } \\
\text { parts }\end{array}$ & $\$ 10.00$ \\
\hline Capacitor & Electronics & $\$ 12.00$ \\
\hline 5V Power Supply & $\begin{array}{l}\text { Gives Power to the Micro Servo } \\
\text { Motor }\end{array}$ & $\$ 16.00$ \\
\hline 12 " $\mathrm{x} 24$ " Plastic plex glass board & The base of the robotic arm & $\$ 21.00$ \\
\hline $\begin{array}{l}\text { HATCHBOX PLA 3D Printer Filament, } \\
\text { Dimensional Accuracy +/- } 0.03 \mathrm{~mm}, 1 \mathrm{~kg} \\
\text { (4 Spool) } 1.75 \mathrm{~mm}\end{array}$ & To make the robotic Arm & $\$ 166.00$ \\
\hline Jumper Wires & Wires & $\$ 20.00$ \\
\hline Miscellaneous & Miscellaneous & $\$ 100.00$ \\
\hline & $\begin{array}{r}\text { Subtotal } \\
\text { Tax } \\
\text { TOTAL }\end{array}$ & $\begin{array}{l}\$ 492.00 \\
\$ 40.54 \\
\$ 532.54\end{array}$ \\
\hline
\end{tabular}

\section{Conclusion and Future Works}

This arm is designed to have cheap materials and proof of concept. In future we plan to make a full mechanical robot to be sent out for different robotics competition. Obviously the budget will be higher, but the structure will be more solid and functioning. A simple demonstration of built prototype can be seen: https://www.youtube.com/watch?v=nkIAu7L0 JU\&feature=youtu.be.

\section{References}

[1] Golzy, J. "A Control Method for the Movement of a Robot Arm along a Prescribed Path." [1990] Proceedings. The Twenty-Second Southeastern Symposium on System Theory, doi:10.1109/ssst.1990.138157.

[2] https://www.arduino.cc/en/reference/servo

[3] https://www.engineersgarage.com/contribution/adaptive-headlights-cars-part-2123

[4] https://www.slideshare.net/AhmedSharos/final-project-56119414J.

[5] Ramon, Manoel Carlos. "Assembling and Controlling a Robotic Arm." SpringerLink, Apress, Berkeley, CA, 1 Jan. 1970, link.springer.com/chapter/10.1007/978-1-4302-6838-3_11.

[6] Ross, Kevin. "Whats a Servo?" Whats a Servo: A Quick Tutorial, www.seattlerobotics.org/guide/servos.html.

[7] "Why Choose Small Industrial Robot Arms." RobotWorx, www.robots.com/blogs/why-choosesmall-industrial-robot-arms.

[8] Yurtoğlu, Nadir. "Http://Www.historystudies.net/Dergi//Birinci-Dunya-Savasinda-Bir-AsayisSorunu-Sebinkarahisar-Ermeni-isyani20181092a4a8f.Pdf." History Studies International Journal of History, vol. 10, no. 7, 2018, pp. 241-264., doi:10.9737/hist.2018.658. 